\title{
Escrita indígena, discurso, resistência e cidadania
}

\author{
Indigenous writing, discourse, resistance and citizenship \\ Águeda Aparecida da Cruz Borges ${ }^{1}$ \\ Universidade Federal de Mato Grosso
}

Aprendi que não é possivel transitar pela linguagem impunimente, para o bem ou para o mal: as máscaras caem, as ilusões se apequenam e as utopias carecem de chão para alçarem voo.

Mariza Vieira da Silva (1998, p.11).

\begin{abstract}
- RESUMO: Tomando o discurso como uma rede, puxo fios para desenvolver algumas reflexões acerca do modo como a pesquisa para a compreensão da língua, da história e os seus efeitos na escrita/sobre uma escrita específica é fundamental no processo de subjetivação da mulher indígena, na materialidade dos textos que produz, considerando as particularidades étnicas. O objetivo amplo do artigo é analisar escritas de Eliana Potiguara, principalmente, sequências discursivas do livro: Metade cara, metade máscara (2004) e a relação que ela estabelece com a língua escrita alfabética como prática de denúncia, de resistência, à revelia dos processos de naturalização, oficialização, convenção linguísticas e interdição da língua própria.

- PALAVRAS-CHAVE: Sujeito mulher indígena; Discurso; Escrita; Eliana Potiguara; Resistência.
\end{abstract}

- ABSTRACT: Taking speech as a network, I draw threads to develop some reflections on how research to understand language, history and their effects on writing / on a specific writing is fundamental in the process of subjectivation of indigenous women, in the materiality of the texts it produces, considering the ethnic particularities. The broad objective of the article is to analyze Eliana Potiguara; writings, especially the discursive sequences of the book: Half Face, Half Mask (2004) and the relationship she establishes with the alphabetic written language as a practice of denunciation, of resistance, without the processes naturalization, officialization, language convention and language prohibition.

- KEYWORDS: Subject indigenous woman; Speech; Writing; Eliana Potiguara; Resistance.

No percurso da pesquisa com povos indígenas, analiso, dentre outros, o funcionamento da memória e história na língua e seus efeitos de sentido, entrelaçando alguns 'fios de uma rede' discursiva, sobre os processos de naturalização, oficialização, convenção e interdição da língua, de modo a mostrar como esses processos são determinantes nos processos de identificação/subjetivação.

Mais recentemente as minhas perguntas têm se voltado para as práticas de resistência de mulheres indígenas de algumas etnias e já foram muitos os aspectos observados, analisados. A proposta que me coloco, neste momento, ainda incipiente,

\footnotetext{
${ }^{1}$ Doutora em Linguística. Professora da Universidade Federal de Mato Grosso/Campus Universitário do Araguaia (UFMT/CUA).).E-mail: guidabcruz@hotmail.com 
apresentei no Enalihc/2018 e materializo neste texto, se pauta no Projeto de pósdoutorado ${ }^{2}$.

Poderia partir de vários pontos e de muitas maneiras esta escrita, mas gosto muito da metáfora da rede proposta por Ferreira (2007, p. 19) "A rede, como um sistema, é um todo organizado, mas não fechado, porque tem os furos, e não estável, porque os sentidos podem passar e chegar por essas brechas a cada momento". Assim, um discurso funcionaria como uma rede e é por aí que puxo fios para desenvolver algumas reflexões acerca do modo como a pesquisa para a compreensão da língua, da história e os seus efeitos na escrita/sobre uma escrita específica, ou seja, de outro modo como se subjetiva o sujeito mulher indígena na materialidade dos textos que produz.

O objetivo amplo da pesquisa é compreender os diferentes processos de constituição do sujeito mulher indígena na relação com a língua escrita alfabética e a pergunta principal, a partir da rede discursiva de materiais e aspectos já analisados no percurso que me traz até aqui, resultante da minha relação com povos indígenas é: Qual fio dessa 'rede discursiva' de aspectos me permitiria entrar no universo complexo de subjetivação de mulheres indígenas pela escrita?

Um dos pontos que levanto para discussão, ainda que não aprofunde neste texto, converge para o fato de que os povos indígenas não são de uma tradição alfabética, no entanto não são ágrafos, pois, cada povo, ao seu modo de significar, traz uma tradição de grafismos que significa conforme a exigência da organização social indígena.

É importante lembrar que, historicamente, a escrita serviu/serve como instrumento de protesto, denúncia social, em que o discurso engajado vem tomando diversas formas de inscrição. Toda escrita é um gesto de interpretação, segundo Orlandi (1996) ou seja, toda tomada de palavra é um gesto de interpretação e a leitura também é uma tomada de palavra do leitor frente aquilo que ele se propõe a ler. Esses gestos de interpretação que sustentam as leituras possíveis, são gestos que se dão na história na relação intríseca com a ideologia, portanto, um funcionamento simbólico do modo como o sujeito se insere na história, logo um processo por meio do qual determinados sentidos ganham corpo, ganham evidência dentro das relações sociais através da língua/gem.

$\mathrm{Na}$ relação: indígenas $\mathrm{X}$ escrita, lembro os autores de La Langue Introuvable (Gadet e Pêcheux, 1984) que trabalham as contradições no jogo do "universal" e do "histórico". Aqui, penso no jogo formado pela língua silenciada dos Potiguara e a língua portuguesa. Os autores mostram como se idealiza um "universal", funcionando simultaneamente, segundo a figura jurídica do Direito e segundo a figura biológica da Vida; uma igualdade ideal que cria, pelo mesmo gesto, a desigualdade real. A língua do Direito - neste caso, portuguesa, representa na língua, "a maneira política de negar a política" (Pêcheux, 1982). Foi assim no estado burguês, e pode-se observar o mesmo movimento no estado capitalista e neoliberal: "para se tornar cidadãos, os homens devem, pois, livrar-se das particularidades históricas que os entrava: seus costumes locais, suas concepções ancestrais, seus preconceitos e sua língua materna" (PÊCHEUX e GADET, 1981, p. 35, grifo nosso, pois tenho evitado essa unificação).

Além disso, "o próprio modelo de igualdade é histórico, projetado num tempo e num espaço definidos" conforme (ALBUQUERQUE, 2007, p.33). O problema discutido por Pêcheux e Gadet contribui para pensar a colonização, no Brasil, a que, durante séculos, os povos indígenas foram submetidos.

\footnotetext{
2 Projeto apresentado e aprovado pelo Programa de Pós-Graduação em Linguística (PPGL), proposto pela Unemat/Cáceres, sob a orientação da profa. Dra. Olimpia Maluf Sousa. (julho/2018 a julho de 2019).
} 
Observemos, em primeiro lugar que a própria expressão "índios" é genérica, universaliza o específico, ignorando as mais de mil etnias diferentes que aqui existiam quando da chegada dos europeus, em segundo lugar, a observação converge para o papel das políticas integracionistas (catequese, missionários, Serviço de Proteção ao Índio - SPI - FUNAI...) que, ao longo dos séculos de colonização, em nome da igualdade, esforçavamse por fazer os indígenas desaparecerem como nações e como identidades na medida em que os processos de educação contribuíram para a desvalorização e, mesmo, para o desaparecimento de suas línguas, da sua religião, dos seus costumes, de sua cultura.

Sabemos que muitos povos indígenas foram catequizados pelos salesianos, como por exemplo os Xavante (com quem trabalhei na minha pesquisa de doutorado). Albuquerque (2017) escreve que nos internatos salesianos, crianças e jovens que não entendessem o Português chegavam a ficar meses sem ter com quem conversar, e outras que tentavam falar com parentes em suas próprias línguas eram castigadas e humilhadas carregando uma tabuleta no peito com os dizeres: "Eu não sei Português", e que só se livravam desse castigo se "entregassem" outro colega que cometesse a mesma "falta". Trata-se de uma prática de língua que fazia calar uma subjetividade, produzindo outra. Tem-se aí, também, a visibilidade das políticas do silenciamento adotada pelos salesianos, pois como afirma Orlandi (1997, p.76), "O dizer e o silenciamento são inseparáveis", ou seja, é a política da interdição do dizer. Pró́bem-se certas palavras para proibir certos sentidos, produzindo, assim, uma humanidade idêntica e identificada, regulada em suas posições e seus fluxos, em uma língua única, legítima, feita de conceitos bem definidos e de significados estáveis, um nome para cada coisa e uma coisa para cada nome (ALBUQUERQUE, p. 272).

Também nesta perspectiva dos apagamentos e silenciamentos, entendemos que é uma "presença ausência", é constitutiva, pois é o silêncio o "laço" metaenunciativo que vem enxertar em um ponto do fio do dizer para então "nomear a falha, abrindo o dizer, pelo dito, sobre o que ele não diz, fazendo ressoar em outras palavras mais esta parte de silêncio que se experimenta nas palavras" (AUTHIER-REVUZ, 2010, p. 257 apud LORENSET, 2017).

Pensando nessa direção e sob os fundamentos da Análise de Discurso como já vimos refletindo, recortei para a produção deste texto, algumas sequências discursivas a partir da leitura de Eliane Potiguara que ficou conhecida pelo potencial escrito no livro: Metade Cara, Metade Máscara (2004). A escrita veio primeiro para registrar as histórias do seu povo em contos, poemas...e posteriormente, como espaço de denúncia e resistência.

É nesse ponto das amarras entre as línguas: a falada, a desenhada, a escrita e os seus efeitos no processo de subjetivação que justifico, também, a escolha desse material como "corpus", qual seja, escritos de uma mulher indígena que foi obrigada a viver fora da aldeia, sendo interditada do seu mundo, da língua própria, mas como veremos a memória é eficaz e funciona na sua tomada de posição como escritora.

Pela língua do outro a do colonizador, a memória retorna e se materializa na escrita possibilitando a inscrição de dizeres de si, às vezes incorporado de uma pluralidade, que se dispersa na ressonância de um clamor por todas as mulheres indígenas. Expõe o porquê do apagamento da história, do silenciamento da língua, da constituição subjetiva e aponta: "a administração da língua enquanto parte de uma nacionalidade leva à cisão entre os conteúdos e formas enunciáveis por escrito e aqueles enunciáveis na oralidade. [...] traços que permanecem daquilo que foi apagado" (PAYER, 1998, p. 160).

Eliane Potiguara se inscreve numa das vozes fortes dentre os povos indígenas e vem se estabelecendo no espaço ocidental, pela ocupação de determinados lugares, um 
protagonismo, sob o nosso parecer, que promove a visibilidade e resistência especialmente de mulheres.

Ela é Conselheira do INBRAPI (Instituto Indígena de Propriedade Intelectual), Coordenadora da Rede de Escritores Indígenas na Internet e do Grupo Mulher IndígenaEducação (GRUMIN) um programa que promove a educação de mulheres indígenas incentivando-as a participar ativamente nas suas comunidades e na sociedade em geral, num trabalho conjunto de preservação e divulgação do conhecimento, das tradições e da cultura ancestral. Assim sendo, o GRUMIN é um espaço de afirmação identitária e de subjetivação indígena livre da carga estereotipada que o pensamento eurocêntrico impõe, historicamente.

Potiguara foi indicada, por seu trabalho como ativista, como representante do Brasil na campanha "Mil Mulheres Para o Prêmio Nobel da Paz 2005". Foi nomeada uma das 10 mulheres do ano em 1988, pelo Conselho das Mulheres do Brasil, por ter criado o GRUMIN. Participou durante anos, da elaboração da "Declaração Universal dos Direitos Indígenas", na ONU em Genebra. Além disso, existem diversos textos sobre ela e por ela, nem por isso considero que não seja importante tomar a sua escrita para construir este texto.

Diante da emergência de vozes, nas condições de produção vigentes, que desestabilizem as narrativas historicamente construídas sobre os povos indígenas, Eliane Potiguara ganha destaque ao utilizar a escrita como mecanismo de resistência às inúmeras tentativas de silenciamento aos povos indígenas e, especificamente, impostas às mulheres como já disse.

A autora se posiciona politicamente como pode ser conferido nas suas manifestações, tanto na forma: ensaios, poesias, conferências e palestras quanto no conteúdo que faz circular através da Internet, em blogs, e-books, boletins eletrônicos, websites pessoais e outros, como o youtube.

Em seu livro Metade cara, metade máscara, numa tomada de posição em que dá corpo à voz feminina, Potiguara escreve textos variados e vai se dispersando em múltiplas vozes de mulheres indígenas, que têm em comum uma história de violência, deslocamentos, imposições silenciamentos, mas, no entanto, constroem uma história de afirmação identitária e de luta pela preservação de seus costumes e ancestralidade.

O povo potiguara por muito tempo foi tido como extinto, como totalmente assimilado ou dizimado pela colonização. É possível perceber tal fato pela pouca produção sobre a etnia, e pela referência a esse povo, assim como em relação a outras etnias como sendo do passado. É nesse contexto que se insere a escrita de Eliane Potiguara. Com o desaparecimento de seu avô, por questões ligadas à luta pela terra, ela e a família se deslocaram para o Rio de Janeiro, onde vivem até hoje, mas como ela mesma escreve, nunca deixou de ser indígena potiguara:

[...] gosto de ser identificada sempre como indígena que é a força maior que eu tenho na minha família, que é minha identidade enquanto povo indígena, povo Potiguara de origem indígena potiguara. (POTIGUARA, 2009).

A condição de indígena fora da aldeia se imprime fortemente na literatura de Potiguara. Com a migração forçada pelo neocolonizador e a falta de condições de sobrevivência nas aldeias, lhe é posto o desafio de ser indígena na cidade, conferindo esse caráter de deslocamento territorial ela escreve:

Eu não tenho minha aldeia/ Minha aldeia é minha casa espiritual/

Deixada pelos meus pais e avós/ A maior herança indígena./ Essa casa 
espiritual/ É onde vivo desde tenra idade/ Ela me ensinou os verdadeiros valores $[\ldots .]$.$" (POTIGUARA, 2004, p. 131).$

A afirmação da indianidade é marcada nos dizeres: Minha aldeia é minha casa espiritual inscritos e impressos na escrita, mostrando que a relação forçada com a sociedade ocidental não foi capaz de matar os verdadeiros valores. Esse é um modo de contrariar os discursos de que indígenas no espaço urbano deixam de ser indígenas, como, também mostrei na tese de doutorado ${ }^{3}$.

Ela própria diz sobre a importância da escrita para se tornarem cidadãs, pois "a oralidade não tem validade na sociedade ocidental, à escrita é que se atribui o valor de documento e sem ela os povos indígenas ficam à mercê de pareceres e análises escritas por não indígenas":

Povos indígenas, povos ressurgidos, emergentes, índios-descendentes, índios desaldeados, 'desplazados' e migrantes grupais ou migrantes individuais não podem ficar à mercê de análises antropológicas burguesas, insensíveis e intolerantes de governos racistas, preconceituosos e autoritários, seja esse ou aquele. As almas dessas pessoas devem ser respeitadas porque têm a história de seus antepassados, têm a história das mulheres e homens decididos (POTIGUARA, 2004, p. 92, grifo meu).

Fazer-se sujeito e produzir sentidos é estar no espaço de memória do dizer, do jádito (interdiscurso), de modo que a constituição do sujeito de escrita circunscreve-se em processos de identificação e subjetivação, por sua relação mesma com a memória discursiva de diferentes materialidades simbólicas, tais como, a língua própria, a oficial... as variedades em que a língua se inscreve...etc. Vejamos como esses processos vão se imprimindo nos dizeres/escritos de Eliana:

Primeiro, eu acho que já estava no Movimento Indígena (MI) desde que nasci. Como era de uma família combatente, guerreira que escapa da morte, foge, tem seu líder assassinado então essa família tentou sobreviver. Segundo, eu tive muita influência da minha avó. Minha avó era uma guerreira muito combativa, mulher analfabeta, indígena bastante consciente de sua condição de mulher, pobre, nordestina e eu ouvi sempre a voz guerreira dessa mulher. Então eu me considero uma pessoa que já vem no MI dentro de casa tendo essa visão. ${ }^{4}$

Reflito, existem várias línguas, a língua é capaz de fazer e desfazer, por ela fazemos sentir/amar. Capaz de repetir, mas também de diferir, se ela não existe nunca na unidade, na homogeneidade, na completude, apesar dos processos de naturalização, oficialização, imposição e outros, e considerando que o sujeito ao ser interpelado pela

\footnotetext{
${ }^{3}$ Da Aldeia para a cidade: processos de identificação/subjetivação do índio Xavante na cidade de Barra do Garças-MT, alteridade irredutível? (2013). Unicamp: SP.

${ }_{4}$ (POTIGUARA, Entrevista para a Tese de Daniel Munduruku, 2009, http://elianepotiguara.blogspot.com/p/entrevistas.html).
} 
ideologia produz-se esse efeito de evidência, de unidade, de completude, penso a relação língua/história/escrita na produção do discurso sobre a língua escrita como fundamental na subjetivação e na resistência dessa mulher, que, de certo modo, ao produzir sentidos a partir do espaço de memória do dizer, do já-dito (interdiscurso) o faz emergindo milhares de vozes sufocadas, de mulheres de outras etnias.

Vale considerar, que ao recortar a subjetividade indígena visamos compreender o funcionamento discursivo dessa prática de linguagem como espaço de constituição e definição desse sujeito, de modo especial, mulher/indígena/escritora/poeta/resistente como a própria poesia:

O que faço com a minha cara de índia? e meus espíritos e minha força e meu tupã e meus círculos? que faço com a minha cara de índia? e meu toré e meu sagrado e meus "cabôcos" e minha terra que faço com a minha cara de índia ? e meu sangue e minha consciência e minha luta e nossos filhos?(...) barriga brasileira ventre sagrado povo brasileiro ventre que gerou o povo brasileiro hoje está só ... a barriga da mãe fecunda e os cânticos que outrora cantavam hoje são gritos de guerra contra o massacre imundo Nosso ancestral dizia: temos vida longa Mas caio da vida (...) range o armamento contra nós Mas enquanto eu tiver o coração aceso Não morre a indígena em mim $E$ nem tampouco os compromissos que assumi Perante os mortos De caminhar com minha gente passo a passo E firme em direção ao sol [...] (POTIGUARA, 2004, p. 102).

Neste caso, a relação de dor/desabafo no processo de produção da escrita pode ser transformada em um objeto teórico, que critique a impressão de "realidade" do pensamento, ilusão que se sobrepõe a palavras, ideias e coisas. Em outras palavras, nos provoca a fazer muitas perguntas, levando em conta que a relação sujeito e escrita não se esgota, principalmente quando se tomada aos olhos da Análise de Discurso, a qual atravessa a transparência da linguagem em determinadas condições de produção. Assim sendo, mobilizo, ainda que como apontamentos, aspectos como a cidadania e a cultura para produzir a reflexão.

O sujeito não nasce cidadão, apesar da pretensa igualdade. O sujeito tem de construir esta posição. Para tal, na nossa sociedade, ser cidadão consiste em ter uma qualidade efetiva no uso da língua nacional. O que estou querendo dizer é que o sujeito deveria estar na posição de sujeito de sua língua e não carecer de outra língua para vir a ser. Quando sua posição é condicionada por um vir a ser, estar ou não na posição legitimada passa a ser de inteira responsabilidade do sujeito e é essa posição de compromisso e responsabilidade, ainda que fora da língua própria, que enxergo a escrita indígena de Eliana. Ela não está na língua própria porque essa foi apagada em determinadas condições na história, mas ela aprende a língua do Outro, escreve na língua do Outro e toma uma posição de se dizer, de se manter indígena e alcançar a dita cidadania.

Outro aspecto, igualmente importante, nessa construção e que tem a ver com o que estou chamando de escrita indígena se transforma em sentidos de uma prática de resistência contra as diferentes formas de poder. Eu diria que estes sentidos tomam também o modo do sujeito se relacionar com a língua interditada historicamente, já que a língua válida é a língua "civilizada" oficializada, para se assegurar num espaço que não é o seu, não é o da sua cultura e se sentir seguro, se sentir pertencente e cidadã no espaço alheio. 
A cultura é determinante nas práticas sociais e a contemporaneidade tem mostrado uma noção de cultura de uma forma frágil. No encontro com a diferença, nos estudos e trabalhos com povos indígenas, passamos a pensar cultura como um processo poroso que impossibilita generalizações que naturalizam o conceito. $\mathrm{Na}$ cultura, por exemplo, se prendem as relações identitárias, pensemos: Eliana Potiguara, como já dissemos, logo cedo foi obrigada, junto à família, a se deslocar da sua aldeia para a cidade, no entanto, ela materializa na sua escrita: Eu não tenho minha aldeia/ Minha aldeia é minha casa espiritual/ Deixada pelos meus pais e avós/ A maior herança indígena./ Essa casa espiritual/ É onde vivo desde tenra idade/ Ela me ensinou os verdadeiros valores [...]" (POTIGUARA, 2004, p. 131). Potiguara não deixou de ser indígena, ela reafirma de outro modo: range o armamento contra nós. Mas enquanto eu tiver o coração aceso, não morre a indígena em mim. A partir do momento que a cultura pode ser descrita de uma forma inteligível com tamanha densidade, ela constitui um significado para o sujeito.

Para Costa (2000), "as sociedades e culturas em que vivemos, são dirigidas por poderosas ordens discursivas que regem o que deve ser dito e o que deve ser calado e os próprios sujeitos não estão isentos desses efeitos". Cada sociedade constitui sua própria cultura através da sua linguagem, dos seus discursos, das suas imagens e suas produções de acordo com a sua realidade, logo podemos dizer que ela cria/produz a sua própria identidade cultural. Portanto, não podemos apenas problematizar questões culturais sob perspectivas de saberes estéticos, intelectuais e espirituais, mas sim como elas são concebidas a tudo que está associado a ela, como se reporta às diversas formas de ver o mundo e o como de fato ele realmente é (COSTA, p. 32).

"Uma cultura nacional é um discurso - um modo de construir sentidos que influenciam e organizam tanto nossas ações quanto a concepção que temos de nós mesmos. As culturas nacionais, ao produzir sentidos sobre a "nação" como diz Hall (1998), é possível nos identificar com esses sentidos. Desse modo, cria-se relações discursivas que nos leva a compreender que a cultura pode ser entendida como um potente espaço para a compreensão da diferença. Para o mesmo autor, deveríamos pensar a cultura como um dispositivo discursivo que representa a diferença como unidade ou identidade. Elas são atravessadas por profundas divisões, sendo "unificadas" apenas através das relações de poder.

Ampliamos, na filiação teórica em que nos propusemos a pensar a escrita indígena de Eliana Potiguara como um lugar disperso entre ser indígena e brasileira, para mim indígena brasileira, constituindo, assim, um espaço denso entre a língua e a história. Venho refletindo, apoiada em autoras como Leandro-Ferreira (2011, p. 56) que a noção de cultura sempre esteve presente na Análise de Discurso, mas como uma presença ausência que vem ganhando cada vez mais destaque nos trabalhos em Análise de Discurso no Brasil. Além disso, por se tratar de uma disciplina de entremeio, conforme escreve Orlandi (2012), ainda se discute com qual(is) teoria(s) é possível um diálogo para se pensar essa noção no aparato teórico da Análise de Discurso, por ser assim, assumi a relação de proximidade com os autores acima mencionados.

Ainda, nessa direção, segundo Leandro-Ferreira (idem), a Antropologia poderia contribuir para a (res)significação da noção de cultura na Análise de Discurso. A autora, ao longo de seu texto, provoca-se e questiona os leitores sobre os possíveis diálogos entre as duas teorias. Dentre as aproximações apontadas pela pesquisadora, interessa-me a de determinação. Ao citar um texto de Levi-Strauss, Leandro-Ferreira (p. 63) se questiona se a determinação não seria um dos pontos de encontro da Antropologia com a Análise de Discurso, já que, assim como o sujeito é duplamente determinado: pelo inconsciente e pela 
ideologia, a cultura é tomada na Antropologia como elemento de determinação de um grupo social sobre outro.

A cultura, assim, para a autora, seria essencial na produção de sentidos como produção de subjetividades, já que o sujeito, a partir de uma posição-sujeito, inserida em uma formação discursiva, e de um lugar social, inserido em uma formação cultural, produziria sentidos. Haveria, dessa forma, um ritual de assujeitamento da cultura que, sendo sem falhas, "deixaria brechas por onde emergiriam com força as singularidades" (ibidem, p.314).

Assim, buscamos efeitos de sentido para os questionamentos que estão implicados nos discursos inscritos na literatura de Eliana, em que o assujeitamento se dá pela língua como uma maneira de tanto fazer emergir a sua escrita, quanto reafirmar a força da mulher indígena na prática literária resistente para se significar, se subjetivar e existir. Como já escrevi há uma pluralidade que ressoa no texto da autora:

Eu acredito que nós hoje temos uma educação diferenciada, temos uma cara de movimento, cara literária, de certa forma demos um pontapé inicial nesses panfletos que a gente fazia, nestes poemas-posters que a gente espalhava por aí, Oração pela Libertação da América Latina, Atos de Amor entre os povos, $\mathrm{O}$ que faço com minha cara de índia...falo como uma pessoa sozinha, como realização pessoal. Então a minha contribuição foi mesmo de criar polêmica. [...], mas me sinto assim uma pessoa que conseguiu dar um pontapé inicial nessa discussão de gênero que não se falava em gênero - depois as instituições internacionais só apoiavam os projetos das organizações sociais indigenistas, só apoiavam projetos se essas instituições tivessem um recorte de gênero e a gente é que falava disso, a gente nem sabia o que era isso, mas a gente já falava de gênero, da participação da mulher, da participação da criança do velho, da viúva, a gente tinha essa preocupação de que essas pessoas tivessem voz. Na parte literária também me considero uma precursora por ter trazido os primeiros textos e jogado no território nacional e deixar ver o que acontecia com este trabalho. ${ }^{5}$

E aconteceu, essa "palavra" que é "sangue e oxigênio" é a manifestação da língua da vida (GADET; PECHEUX, 2010, p. 21) na conjuntura traçada pelo subterrâneo das loucuras linguageiras, nas quais o tempero da cultura emerge.

Cultura, resistência, cidadania brotam das palavras de Potiguara e deixam transpirar a essência indígena. Essa escrita legitimada pela língua portuguesa, alfabética pelo apagamento das outras tantas línguas.

Parafraseio (LORENSET, 2017), na história do Brasil acontece um apagamento original e instaurador de sentidos para a língua brasileira: o apagamento de nossa oralidade de país colonizado - as línguas indígenas - e, posteriormente, a língua geral. Mas, sob este apagamento outras línguas se constituíram. No século XIX é o apagamento destas outras línguas que se dá, para as quais não estão abertos os espaços de legitimação sob a forma de uma unidade linguística, o que as restringe a um espaço de significação demarcado pelo sentido da oralidade. As línguas que se apagam, sob o rótulo de oralidades, no momento oportuno, como já dito, tratarei dessa questão, pois considero que a demarcação se dá, também, por outras grafias significativas, conforme apontei no início deste texto:

5 (POTIGUARA, Entrevista para a Tese de Daniel Munduruku, 2009, http://elianepotiguara.blogspot.com/p/entrevistas.html) 
A existência dos grafismos, nestas sociedades, permitiria questionar ou, ao menos, relativizar sua definição corrente como 'sociedades ágrafas' (...) A arte gráfica, enquanto sistema de comunicação visual, permite, portanto, o exercício da memória social (...) ao revelar-se como exercício de repetição de motivos e estilos definidores de cada cultura em especial, e como campo fértil de expressão da criatividade individual, da incorporação de temas, motivos, técnicas, significados e dimensões que, ao mesmo tempo, refletem o momento histórico vivenciado com os desafios e acomodações que exige, a percepção individual do processo e a base cultural, a tradição compartilhada, a partir da qual o artista constitui sua visão e seu modo de expressão e se mostra como representante de seu grupo e de seu povo (VIDAL E SILVA, apud VIDAL, $1992: 293$ ).

Essa discussão produz um processo conflituoso que abre a possibilidade de abordarmos uma série de questões, mas que o espaço deste texto limita. Reflitamos:

Se ao dizer significamos o mundo, não podemos transportar o nosso mundo indígena no dizer indígena, no dizer em sua própria língua. Há que se perscrutar a história dos sentidos em línguas indígenas. Ouvir é o melhor caminho. Pois não é exatamente isso o que o discurso xamâmico evoca? O que os rituais consubstancializam? O que o discurso cotidiano materializa? A questão que se coloca para nós, linguistas interessados em estudar as produtividades de sentidos nas línguas indígenas, é como alcançar a robustez da memória discursiva que dá sentido e profundidade histórica aos sentidos nas línguas indígenas.

Uma das maneiras que encontrei de mergulhar na história dos sentidos nas línguas indígenas foi começar a identificar as projeções ocidentais sobre essas línguas e tentar entender de onde elas vêm para poder argumentar que essas projeções são meras projeções e não são fatos linguísticos universais. São apenas projeções que se tornaram verdades linguísticas e se dispersaram por meio do papel desempenhado pelos europeus no mundo. $\mathrm{O}$ vasto mundo subterrâneo da nossa memória discursiva me deu a apavorante noção de que tamanha empreitada seria impossível. A proposta de revolver camada após camada de sentidos é árdua, mas traz resultados satisfatórios. É uma atividade que se desdobra em duas frentes de trabalho. Em primeiro lugar, investigar as profundezas de nossa memória discursiva. Em segundo, ao reconhecer os limites do sentido produzido por nossas elaborações, buscar ouvir os sentidos emudecidos das línguas indígenas. Se não existe discurso sem sujeito, então seria preciso saber como se produz o sujeito indígena. Não o "sujeito" indígena em relação ao Estado, mas o sujeito indígena enquanto sujeito para seus pares. Ser "gente" implica atitudes, tempo de vida, rituais, dependendo de que grupo estamos falando teremos um "sujeito" diferente e ele não será necessariamente igual ao sujeito ocidental, nem em sua forma de fazer o sujeito nem no sentido de sujeito, nem no corpo de um sujeito. Sendo a construção do sentido de pessoa ou de sujeito fruto da relação histórica com o meio e com os outros não haverá "pessoas" nem sujeitos, no sentido coletivo que há na experiência humana, que signifiquem a mesma coisa, porque não significam a mesma construção, nem a mesma relação. A "pessoa" é um sentido construído a partir de uma relação com determinado ambiente o

Traços de Linguagem, Cáceres, v. 3, n. 1, p. 16-27, 2019. 
que gera diferentes "pessoas" expressas por diferentes discursos. O contato entre estas diferentes "pessoas" e seus diferentes discursos provoca choques de compreensão ${ }^{6}$.

É na perspectiva em que se inscreve Laísa, como muita propriedade, que coloco os meus óculos, copio dela a citação acima porque se a parafraseasse os sentidos dispersariam.

O modo como mulheres indígenas, no silenciamento de suas línguas, se apoderam da língua do Outro é o objeto em que o ponto das amarras entre línguas faladas, escritas, desenhadas e os seus efeitos no processo de subjetivação me impulsionam no desenvolvimento da proposta de seguir na tentativa em dar corpo à compreensão desse entremeio.

A condição de mulher indígena que usa a escrita como instrumento de luta em favor dos direitos de seu povo, coloca a autora em posição de singularidade no contexto da literatura brasileira. A invisibilidade de uma teoria da literatura indígena já sinaliza a falta de reconhecimento. $\mathrm{O}$ espaço ocupado tanto no meio acadêmico, quanto em bibliotecas, livrarias precisa ser ampliado. Eliana Potiguara é um exemplar, dentre tantas outras mulheres indígenas que vêm se ocupando da escrita indígena.

Em Metade cara, metade máscara, como pudemos conferir as palavras abrem passagem da poesia à denúncia desde o genocídio ao desaldeamento histórico e perverso, numa escrita consciente da necessidade de conhecer a trajetória histórica de seu povo como forma de viver com dignidade o presente e assegurar a singularidade de sua cultura numa sociedade balizada pela homegeneização, como ela diz:

No dia que eu conseguir abrir as páginas de minh'alma e contar essas linhas de meu inconsciente coletivo - com alegrias ou dores, com prazeres ou desprazeres, com amores ou ódios, no céu ou na terra - aí sim, aí sim, vou soltar a minha voz num grito estrangulado, sufocado há cinco séculos. Quinhentos anos, de pretenso reconhecimento de nossa cidadania, não pagam o sangue derramado pelas bisavós, avós, mães e filhas indígenas deste país. Este dia certamente chegará, mesmo que eu esteja em outros planos (p. 9).

Ao entrarmos em contato com a sua obra escrita mergulhamos em um universo múltiplo e plural em todos os sentidos, pois seus textos trazem reflexões sobre a trajetória de vida engajada da autora. Sua literatura transita entre uma poética de confronto e de relação, acarretando em uma análise da articulação entre o imaginário do espaço e as estratégias de um posicionamento identitário de subjetivação pois, não mudamos nada da situação dos povos do mundo se não transformarmos o imaginário, ou seja, a ideia de que a identidade seja de raiz única, fixa e intolerante, ela não o é.

É necessário rever a Totalidade - Mundo a partir do nosso lugar e do outro, estabelecendo relações e não evidenciando a separação, exclusão, segregação. Portanto, a condição de mulher indígena, que usa a escrita como instrumento de luta em favor dos direitos de seu povo, coloca a autora em posição de singularidade discursiva nesse

\footnotetext{
${ }^{6}$ FERNANDES, T. L. Os espelhos do jaguar e o que seus olhos viram na outra margem do rio. Repensando o discurso científico sobre as línguas indígenas / Tese (doutorado) Orientada por Eduardo Roberto Junqueira Guimarães, Campinas, SP: [s.n.], 2017.
} 
acontecimento, pois toda escrita é tributária de seu tempo, em que pesem os lugares de ruptura e de resistência.

\section{REFERÊNCIAS}

ALBUQUERQUE, J. G. Educação escolar indígena: do panóptico a um espaço possível de subjetivação na resistência. Tese de doutorado UNICAMP, sob a orientação de ZOPPIFONTANA, M.G. em Campinas, SP, 2007.

BORGES, Á. A. da C. Sujeito/espaço/língua e memória: relações histórias. In: PAYER, Maria Onice; CELADA, María Teresa (Orgs.). Subjetivação e Processos de identificação: sujeitos e línguas em práticas discursivas - inflexões no ensino. Campinas, SP: Pontes Editores, 2016.

(2013) "Da aldeia para a cidade: processos de identificação/subjetivação do índio Xavante na cidade de Barra do Garças/MT, alteridade irredutível?" Tese de doutorado. Orientadora: Mònica Graciela Zoppi-Fontana. Universidade Estadual de Campinas/UNICAMP, Instituto de Estudos da Linguagem/IEL. Campinas, SP : [s.n.]. COSTA, M. V. Sujeitos e subjetividades nas tramas da linguagem e da cultura. In: CANDAU, V. (Org.) Cultura, linguagem e subjetividade no ensinar e aprender. Rio de Janeiro: DP\&A editora, 2001, p. 29-45.

DIAS, L.F. Os Sentidos do Idioma Nacional: as bases enunciativas do nacionalismo linguístico no Brasil. Pontes, Campinas, 1996.

Entrevista com Eliane Potiguara para tese de doutorado de Daniel Munduruku. (2009)

Disponível em: < http://elianepotiguara.blogspot.com/p/entrevistas.html $>$ Acesso em 22 de fevereiro de 2019.

FERNANDES, T. L. Os espelhos do jaguar e o que seus olhos viram na outra margem do rio. Repensando o discurso científico sobre as línguas indígenas / Tese (doutorado) Orientada por Eduardo Roberto Junqueira Guimarães, Campinas, SP : [s.n.], 2017. FERREIRA, M. C. L. O quadro atual da Análise de Discurso no Brasil In: INDURSKY, F. \& FERREIRA, M.C.L. (Orgs.). Análise de Discurso no Brasil: mapeando conceitos, confrontando limites. Claraluz, São Carlos, SP, 2007.

GADET, F. \& PÊCHEUX, M. A Língua Inatingível. Tradução: Bethânia Mariani e Maria Elizabeth Chaves de Mello. Campinas, Pontes, 2004.

HALL, S. A identidade cultural na pós-modernidade. Rio de Janeiro: DP\&A, 1998.

MARIANI, B. M. Ideologia e inconsciente na constituição do sujeito. Gragoatá, Niterói, n. [?]: linguagem, língua e discurso, 1996.

ORLANDI, E. P. (1999). Análise de Discurso - princípios e procedimentos. Campinas: Pontes, 2005.

. Discurso em Análise: Sujeito, Sentido, Ideologia. Campinas, SP, Pontes, 2012.

PAULO FILHO, P. A revolução da palavra: uma visão do homo loquens. 2. ed. São

Paulo: Siciliano, 1987.

PAYER, M. O. Memória da língua. Imigração e nacionalidade. 1999. Tese de Doutorado (Doutorado em Linguística). Universidade Estadual de Campinas. Campinas, SP: 1999. POTIGUARA, E. Metade Cara, Metade Máscara. São Paulo: Global, 2004.

SANTANA DO NASCIMENTO, F. A. Ler a cultura hoje: a construção do consenso nas políticas culturais do Estado brasileiro. Revista Rua, Campinas, Número 23 - Volume 2, Novembro 2017 | p. $311-334$ 
SILVA, M. V. da. História da alfabetização no Brasil: a constituição de sentido e do sujeito da escolarização. 1998. Tese. Doutorado em Linguística. Instituto de Estudos da Linguagem, Universidade Estadual de Campinas. Campinas, 1998.

VIDAL, L. Iconografia e Grafismos Indígenas, uma introdução. In: VIDAL, L. Grafismo Indígena: estudos de antropologia estética. São Paulo, Studio Nobel/FAPESP/EDUSP, 1992.

Recebido em: fevereiro de 2019.

Aprovado em: maio de 2019.

\section{Como citar este trabalho:}

BORGES, Á. A. da C. Escrita indígena, discurso, resistência e cidadania. Traços de linguagem. V.3 , n.1. , p.16-27, 2019. 